\title{
ARTICLE
}

\section{Paraphilias and paraphilic disorders: diagnosis, assessment and management}

\author{
Jessica Yakeley \& Heather Wood
}

\begin{abstract}
Jessica Yakeley is a consultant psychiatrist in forensic psychotherapy at the Portman Clinic, and Director of Medical Education and Associate Medical Director at the Tavistock and Portman NHS Foundation Trust. The Portman Clinic specialises in the treatment of paraphilias, criminality, violent and antisocial behaviour. Heather Wood is a consultant clinical psychologist and adult psychotherapist at the Portman Clinic, Tavistock and Portman NHS Foundation Trust.

Correspondence Dr Jessica Yakeley, Portman Clinic, 8 Fitzjohns Avenue, London NW3 5NA, UK. Email: jyakeley@tavi-port.nhs.uk
\end{abstract}

\begin{abstract}
SUMMARY
We outline the difficulties in classifying paraphilias as mental disorder and summarise the changes to this diagnostic category in DSM-5. We review the research on the epidemiology and aetiology of paraphilias, and provide guidance on assessment and referral options for general psychiatrists when they encounter patients who may meet diagnostic criteria for a paraphilic disorder. Empirical evidence for effective treatments for paraphilias is limited, and specific treatment services are scarce, particularly for individuals presenting with legal paraphilias or those who are committing paraphilic sexual offences but who have not been convicted.

\section{LEARNING OBJECTIVES}

- Be able to diagnose a paraphilic disorder according to DSM-5 criteria.

- Understand the epidemiology, comorbidity and theories of aetiology of paraphilic disorders.

- Know how to assess the need for disclosure if the patient presents with illegal paraphilias.

\section{DECLARATION OF INTEREST}

None.
\end{abstract}

The designation of paraphilias (Box 1) as a medical disorder has aroused much debate and disagreement over the years. Many rightly object to the pathologising of sexual activities that some consider a lifestyle choice between consenting adults. Nevertheless, people suffering considerable distress from sexual fantasies and behaviours that they find difficult to control continue to be referred

BOX 1 DSM-5 definition of paraphilia

'[A]ny intense and persistent sexual interest other than sexual interest in genital stimulation or preparatory fondling with phenotypically normal, physically mature, consenting human partners.'

(American Psychiatric Association 2013a: p. 685) to general mental health services, presenting psychiatrists with complex diagnostic, ethical and treatment challenges.

\section{Problems with diagnosis and classification Medicalisation of sexuality}

Many psychiatrists do not equate paraphilic behaviours or fantasies with psychopathology or mental illness, and engaging mental health services in providing appropriate assessment, treatment and liaison with criminal justice agencies remains a challenge. DSM-IV-TR attempted to clarify when a paraphilia might be deemed pathological by delineating two distinct criteria that had to be fulfilled before the diagnosis could be made: that an abnormal sexual focus be present for at least 6 months; and that the paraphilia must cause 'clinically significant distress or impairment in social, occupational, or other important areas of functioning' (American Psychiatric Association 2000: p. 523). However, anomalies remained: for example, a man who habitually dresses in women's clothing because it makes him feel sexually excited could not be classified as a fetishistic transvestite according to these criteria unless he felt distressed or impaired by the activity.

\section{Normality v. abnormality}

The DSM does not clearly distinguish between sexual deviance, sexual offending and paraphilias. Sexual deviance is a moral construct that refers to sexual behaviours that contravene the mores of the particular society or culture. It is often equated with sexual abnormality, although this may reflect the general perception of what should be normal rather than what people really do (Grubin 2008).

Attempts to define sexual deviance in purely statistical terms are problematic: what is considered sexually deviant may change over time (e.g. homosexuality); what many cultures consider deviant is the norm in certain subcultures (e.g. fetishistic behaviours in pubertal boys of the Sambian tribe in Papua New Guinea (Bhugra 2010)); and quantifying sexual behaviour and 
determining an appropriate cut-off for abnormal behaviour is difficult. The Kinsey reports on male and female sexuality in the USA in the 1940s and 1950s (Kinsey 1948, 1953) exposed the wide range of unusual sexual practices that were found to be more common in the general public than had previously been acknowledged.

\section{Relationship with criminality and sexual offending}

A further important limitation to the current diagnostic criteria for paraphilias is the confusion regarding their relationship with sexual offending and criminality. Not all sex offenders have paraphilias and most people with paraphilias do not commit offences (Federoff 2009). Certain paraphilias - such as paedophilia, voyeurism and exhibitionism - are illegal if enacted, although it is not illegal to have fantasies or urges to enact. But many other forms of sexual behaviour that would be classified as paraphilias - such as fetishism, cross-dressing and coprophilia - are not illegal, although some may seem bizarre or evoke disgust.

Some have objected to the medicalisation of criminal offences and the potential misuse of psychiatry in diagnosing mental disorder in sexual offenders to legitimise long-term involuntary psychiatric commitment to protect the public (Frances 2011). The DSM-5 development team considered including a new disorder (paraphilic coercive disorder) for people who experienced recurrent and intense sexual arousal from sexual coercion and sought sexual stimulation from forcing sex on three or more non-consenting persons on separate occasions (American Psychiatric Association 2013a). The proposal was rejected on the grounds that it would unjustifiably transform the crime of repeated rape into a mental disorder (Zonana 2011).

\section{Focus on behaviours}

Although a necessary starting point, a sole focus on paraphilic behaviours invites judgement rather than understanding, and risks confounding the important distinction between sexual deviance (as defined socially and legally) and mental disorder. A more satisfactory model of paraphilias would be to describe and understand the phenomenology and psychopathology of sexual fantasy and desire (Grubin 2008). For example, repeated rape is a behaviour, whereas sexually sadistic fantasy is a form of psychopathology that is rare even in rapists, but important to identify as it has implications for management and treatment.

Alternative models of paraphilic behaviour have been proposed in which sexually problematic behaviours have been conceptualised as manifestations of other disorders - for example, the obsessive-compulsive spectrum, mood disorders, attention-deficit hyperactivity disorder and personality disorders - on the basis of common underlying features such as poor impulse control and emotional dysregulation.

\section{Poor reliability and validity}

The DSM diagnostic classification of paraphilias has been criticised for its poor reliability and validity (Zander 2008), and patients often fulfil diagnostic criteria for several different paraphilias concurrently. Although eight different paraphilias are specified in DSM-5 (Box 2), more than 100 unique paraphilias have been described in the literature (Federoff 2010). This exposes one of the limitations of the DSM classification as a whole: it is based on descriptions of symptoms and behaviours rather than on underlying psychopathological mechanisms or aetiology. DSMIV diagnostic criteria have also been criticised for their vagueness (e.g. what is meant by recurrent and intense in Criterion A) and the arbitrariness in the stipulation that the person must experience the paraphilia for 6 months before the diagnosis can be made (O'Donohue 2000).

\section{Compulsive sexual activity and sex addiction}

There has been much debate as to whether people have a mental disorder if they experience recurrent and intense sexual fantasies, urges or behaviours that they feel compelled to act out and that cause

BOX 2 DSM-5 specified paraphilic disorders

- Voyeuristic disorder (spying on others engaged in private activities)

- Exhibitionistic disorder (exposing the genitals)

- Frotteuristic disorder (touching or rubbing against a non-consenting individual)

- Sexual masochism disorder (undergoing humiliation, bondage or suffering)

- Sexual sadism disorder (inflicting humiliation, bondage or suffering)

- Paedophilic disorder (sexual focus on children)

- Fetishistic disorder (using non-living objects or having a highly specific focus on non-genital body parts)

- Transvestic disorder (engaging in sexually arousing cross-dressing)

'Other specified paraphilic disorder': includes zoophilia (animals), scatalogia (obscene phone calls), necrophilia (corpses), coprophilia (faeces), klismaphilia (enemas), urophilia (urine)

(American Psychiatric Association 2013a: pp. 685, 705) 
distress to themselves or others, such as excessive masturbation, use of pornography, sex with consenting adults, cybersex or visiting strip clubs.

Internet sex addiction, in which the person excessively seeks out internet-based sexual activities to the detriment of their personal relationships and occupation, has recently received attention and there is discussion of whether it can be conceptualised as an impulse control disorder similar to gambling (Dunn 2012).

The DSM-5 development team considered inclusion of a new type of paraphilic disorder termed 'hypersexual disorder', but ultimately rejected it because of concerns that it might pathologise normal activity, particularly in younger adults. Nevertheless, many individuals with paraphilias display a compulsive, out-of-control quality to their sexual activities. Moreover, sexual preoccupation and hypersexuality have been identified as risk factors specifically associated with sexual offender recidivism and paraphilias (Kafka 1997, 2003; Hanson 2004) and therefore are important behaviours to identify and address in men with paraphilias.

ICD-10 does contain a diagnosis of excessive sexual drive, listed under the broader category of 'Sexual dysfunction, not caused by organic disorder or disease' (World Health Organization 1992).

\section{DSM-5}

DSM-5 (American Psychiatric Association 2013a) goes some way in addressing these difficulties. It seeks to more clearly differentiate between atypical human behaviour that is not pathological and behaviour that constitutes a mental disorder. In the case of paraphilias, a new distinction is made between a paraphilia (atypical sexual interest or behaviour) and a paraphilic disorder (a mental disorder stemming from the atypical behaviour). To be diagnosed with a paraphilic disorder, DSM-5 (American Psychiatric Association 2013b) requires that the individual, over a period of at least 6 months:

- feels personal distress about their interest, not merely distress resulting from society's disapproval; or

- has a sexual desire or behaviour that involves another person's psychological distress, injury or death, or a desire for sexual behaviours involving unwilling persons or persons unable to give legal consent.

This change makes it possible for an individual to engage in consensual atypical sexual behaviour without inappropriately being labelled with a mental disorder.

\section{ICD-10}

In ICD-10 (World Health Organization 1992), the paraphilias are classified as disorders of sexual preference. Six specific disorders are listed: fetishism, fetishistic transvestism, exhibitionism, voyeurism, pedophilia and sadomasochism. Three further categories denote 'multiple disorders of sexual preference', 'other disorders of sexual preference' and 'disorder of sexual preference, unspecified'.

\section{Epidemiology}

Reliable studies of the prevalence of paraphilias are limited owing to the reluctance of individuals to report criminal activities or those that they consider shameful. Individuals who receive treatment are more likely to be referred for legal reasons rather than presenting voluntarily, and probably constitute only a small proportion of the total population with paraphilias.

One of the mostly widely quoted studies of sexuality and behaviour was a survey of 2450 randomly selected adults (18 and 60 years of age) carried out in Sweden in 1996, which included questions addressing paraphilias and other problem behaviours (Langstrom 2005, 2006a,b). Of the sample, $3.1 \%$ reported at least one incident of exhibitionism and $7.7 \%$ admitted to voyeuristic behaviour. Men were twice as likely as women to expose themselves and three times more likely to engage in voyeurism. In this study, $2.8 \%$ of men and $0.4 \%$ of women reported at least one incident of transvestic fetishism. These paraphilic behaviours were associated with greater drug and alcohol use, having more psychological problems, same-gender sexual experiences, and childhood histories of parental separation and sexual abuse.

\section{Psychiatric populations}

Studies examining the prevalence of paraphilias in psychiatric populations are rare, but one (Marsh 2010) reported that $13.4 \%$ of psychiatric inpatients had a DSM-IV paraphilia. Such patients were more likely to have been previously admitted to hospital and to have attempted suicide than patients without paraphilias.

\section{Forensic populations}

As would be expected, paraphilias are more commonly found in forensic populations, with rates between 25 and 75\% in sex offenders (Raymond 1999; Dunsieth 2004; Hanson 2007). The wide variation in reported prevalence may be due to the differing characteristics of the study samples. The Raymond and Dunsieth studies were in specialist 
clinical services, so may have overestimated the prevalence, whereas the Hanson study, which gave a much lower figure of about $25 \%$, was of a community sample of sex offenders managed by probation, so may have underestimated the rate. Although serious sexual violence in people with paraphilias is rare, up to $80 \%$ of sexual murderers have a history of paraphilic behaviours (Hill 2007).

\section{Content of pornography}

One strategy that has been used to investigate the prevalence of various paraphilias has been through indirect measures, such as examining the content of pornography (Bhugra 2010). Dietz $\&$ Evans (1982) looked at the covers and content of pornographic magazines and found that bondage and domination constituted the most common imagery.

In recent years, the internet has graphically demonstrated the vast range of unusual sexual interests - both legal and illegal - that are promoted in online pornography and forums such as chat rooms and social networking websites. It is difficult to know how many people are accessing these websites and whether they are being used solely to gratify fantasies or whether they reflect enacted behaviour.

Most concerning, however, has been the rise in the number of people convicted for child pornography offences, which has increased fivefold between 1999 and 2005 in England and Wales (Middleton 2009), with over 1400 such convictions in 2011 (Ministry of Justice, personal communication statistics enquiry, 2013). Not all of these individuals will be primarily paedophilic in their sexual orientation, and very few commit contact offences against children. Nevertheless, this is a worrying trend and a challenge for mental health services, which are seeing a corresponding increase in people referred for help with such difficulties.

\section{Comorbid psychiatric conditions}

Most studies of comorbidity have been conducted among samples of sex offenders and have not distinguished between those with paraphilias and those without. High rates of comorbid mental illness and personality disorder have been reported (Guidry 2004). Mood and anxiety disorders are most prevalent and the presence of multiple paraphilias correlates with higher levels of psychiatric morbidity. Alcohol and substance misuse are also common. Comorbid psychotic illness and paraphilia is rare but when present raises complex problems of risk and management (Kafka 2002; Ahlmeyer 2003). A range of personality disorders, including Cluster B (antisocial, narcissistic and borderline) and Cluster C (avoidant, dependent and obsessivecompulsive), have also been found to be more common in paraphilic sexual offenders than in non-paraphilic offenders (Leue 2004; Bogaerts 2006, 2008).

\section{Aetiological models}

\section{Theories of sexual offending and paraphilias}

The absence of a universally accepted theory regarding the development of normal sexuality makes any theorising about deviant sexuality problematic. Most of the research into the aetiology of paraphilias has been in the area of child sex offending and paedophilia. Empirical studies have shown an increased prevalence of various factors in people with paedophilia and other paraphilias, compared with controls. These include a history of sexual abuse in childhood (Jesperson 2009; Seto 2010; Ogloff 2012), attachment difficulties (Lyn 2004; Marsa 2004; Bogaerts 2005), social incompetence (Dreznick 2003; Seto 2010), emotional dysregulation (Chantry 1994; Ahlmeyer 2003; Seto 2010), and disinhibition caused by empathy deficits (Chaplin 1995; Seto 2010) and substance misuse (Abracen 2000; Looman 2004; Seto 2010).

More recently, attention has been focused on neurodevelopmental abnormalities found in people with paraphilias, such as lower IQ (Blanchard 1999; Cantor 2004; Kruger 2011), increase in left-handedness (Cantor 2004), impaired cognitive abilities (Langevin 1988, 1989; Suchy 2009; Kruger 2011), neuroendocrine differences (especially those involving the serotonergic system; Maes 2001a,b) and neuroradiological brain abnormalities, especially those affecting the temporal (Cohen 2002) and frontocortical regions (Wright 1990; Cohen 2002; Schiffer 2007).

Various aetiological models based on different theoretical paradigms have been proposed to explain the association between these factors and sexual offending. Factors implicated range from psychoanalytic, social learning, cognitivebehavioural, cultural, feminist, attachment and evolutionary to genetic and neurodevelopmental. With the recognition that sexual offending is multiply determined, several comprehensive, multifactorial theories have been proposed (e.g. Finklehor 1984; Marshall 1990, 2000; Hall 1992).

Ward and colleagues (2002, 2006a) integrate elements of preceding models into an overarching framework to explain sexual offending in general, attempting to include evolutionary selection, 
neurobiological functioning, learning and psychological systems associated with emotional problems, social difficulties, cognitive distortion and deviant sexual arousal. They propose that there are multiple pathways to child sex offending and sexual offending in general, based on four clusters of clinical problems: intimacy and social skills deficits; cognitive distortions; emotional dysregulation; and distorted sexual scripts manifesting in sexual fantasies and arousal involving children. Each cluster is associated with a particular pathway to offending. A fifth pathway represents sexual offences by antisocial individuals who engage in a wide variety of criminal acts.

\section{Psychodynamic models}

The aforementioned theories are focused on sexual offending rather than paraphilias per se, and they tend not to consider psychodynamic or psychoanalytic concepts, particularly those of defence and conflict. A psychodynamic model of paraphilias may complement and add meaning to a neurodevelopmental model by viewing the paraphilic fantasies and behaviours as sexualised forms of defence against underlying personality difficulties, anxieties or conflicts, particularly those concerning emotional intimacy (Wood 2013). The sense of excitement and empowerment that the paraphilia offers may be seen as an antidote to feelings of helplessness, powerlessness or inadequacy. Many patients with paraphilias describe a very disturbed sense of self in which feelings of self-disgust, shame and humiliation predominate.

Many of the patients with paraphilias that we treat at the Portman Clinic in London describe histories of childhood trauma, abuse or rejection by parents or carers who showed excessive aggression or neglect. These patients may have been prematurely exposed to adult sexuality via overt sexual abuse in childhood or disturbing pornography in early adolescence. Such premature sexualisation interferes with the young person's normal sexual developmental trajectory, and sexual impulses may become confused with aggressive impulses arising from prior experiences of maltreatment or neglect. Paraphilic fantasies which often emerge in adolescence as an escape from painful feelings and traumatic experiences - may progress to paraphilic behaviours that can become habitual and dominate the person's social and interpersonal relationships. The paraphilic act bestows a powerful sense of excitement, control and triumph, and creates a scenario in which the dreaded situation - that of being overwhelmed or completely controlled by another, as in the original childhood experience - is reversed. Hostility, secrecy, self-deception and collusion are characteristic of the paraphilic act, but also are features that may pervade the person's relationships to self and others in general (Ruszczynski 2007).

\section{Assessment}

\section{Motivation for treatment}

Some patients present to general mental health services specifically for treatment of a paraphilic disorder, whereas others are referred for another mental disorder, such as depression, and it later emerges that they have paraphilic fantasies and behaviours.

People who have been convicted for illegal paraphilias and are mandated to undergo treatment as part of their sentence may be less motivated to engage in treatment than patients presenting voluntarily. Motivation may fluctuate according to internal and external factors and it is important to assess how the person feels about their fantasies and behaviours, what their aims for treatment are and why they have sought help (if they have) at this time. It is important for staff to facilitate engagement by the use of motivational techniques such as empathic understanding, mutual trust and acceptance, empowering patients to choose to engage rather than feeling that treatment is imposed on them.

\section{Nature and history of paraphilic behaviours}

The assessing clinician should delineate the person's specific paraphilic fantasies and behaviour, their onset, history and duration. Many people with paraphilic disorders give a long-standing history of paraphilic fantasies and behaviours which often goes back to adolescence. Although it may be important for the patient to explore possible distal factors associated with the onset of their behaviours (e.g. a history of sexual abuse or premature exposure to pornography or parental sexuality) to provide some understanding and meaning for their paraphilia, such explanations may also be used by the patient to justify and minimise their damaging behaviours. It is important to establish proximal and contextual factors related to the paraphilic acts, such as disinhibition due to drug or alcohol misuse.

\section{Multiple paraphilias}

The clinician should also ascertain whether the person has multiple paraphilias and assess the range of sexual urges, interests and behaviours both currently and longitudinally, as these may 
change over time. People may not easily admit to the extent of their unusual sexual interests and activities because of feelings of shame and selfdisgust. For example, a patient may readily admit to compulsively seeking anal sexual encounters with strangers in which he is dominated and controlled, but be reluctant to admit that he also has a longstanding history of cross-dressing of which he is very ashamed but resistant to giving up.

\section{Illegal paraphilias}

Patients presenting with illegal paraphilias may be even more reluctant to talk about them in any detail because they fear the legal consequences of disclosure. In such cases, a degree of minimisation of the seriousness of ongoing offences, if not outright denial, is common. However, there is little evidence to support the commonly held view that individuals who minimise their offending behaviours pose an increased risk and respond less well to treatment.

Patients referred for psychological treatment after they have served a prison sentence for an illegal paraphilic disorder may be reluctant to admit that they still have paraphilic fantasies, let alone that they are still enacting them.

Some patients present for help with legal paraphilias but it subsequently emerges that they are also engaging in illegal paraphilic behaviours for which they have never been convicted. It is important to ask about illegal activities even if the patient has no prior criminal record.

Confidentiality and disclosure are discussed at the end of this section.

\section{Degree of associated distress to self and others}

For a formal diagnosis of paraphilic disorder, the behaviour must cause significant distress to the individual and/or to others. Many individuals present for help because paraphilic behaviours have come to dominate their lives to the detriment of their relationships and/or work (Box 3).

It can be particularly difficult to ascertain the degree of distress or harm that individuals with paraphilias cause to others. Illegal paraphilias, by definition, constitute sexual offences by causing physical and/or psychological harm to non-consenting individuals or by breaching the privacy of those individuals, as in voyeurism. However, even if a person admits to the offence, deficits in empathy or cognitive distortions can make it difficult for them to fully recognise and understand its impact on others.

Legal fantasies and paraphilias can also adversely affect the individual's relationships in ways that they may minimise or not acknowledge.
Apparently consenting partners may complain of the time taken up by their partner's sexual proclivities at the expense of their own needs and desires or say that they 'go along' with their partner's fantasies but do not really enjoy them.

Keeping paraphilic interests a secret from a partner can have obvious deleterious consequences for the relationship - for example, lies to cover meetings with prostitutes can foster suspicion and mistrust, or money spent on sex chat lines may be syphoned from household accounts. The lying and deception involved can also have more subtle but equally damaging effects and they sometimes become a prominent aspect of the person's mode of relating to others in general.

\section{Third-party information and objective measures}

A thorough review of previous records (including medical records) and documentation and, in cases of offending, police records, victim statements and pre-sentence reports, may be essential to gain a full history. In some cases, particularly where there appears to be some degree of denial of offending behaviour, it may be appropriate also to obtain the views of third parties such as parents or other relatives (e.g. in the case of a juvenile offender) or involved professionals such as the person's probation officer.

\section{Assessment of sexual intent}

Although not used as routinely in the UK as in the USA and other countries, specific physiological and neuropsychological tests may be useful in the assessment of paraphilias. Penile plethysmography (PPG) has historically been a standard tool for the assessment and measurement of deviant sexual arousal, exposing the individual to visual or auditory stimuli to assess their penile responsiveness. However, more recently its usefulness has been questioned on the grounds of concerns regarding standardisation, reliability and validity (Marshall 2006).

\section{B0X 3 When paraphilia dominates a life}

Mr A presented for help for his compulsive use of prostitutes, whom he would get to spank him and urinate on him. He was frequenting brothels two or three times a day. He was consequently in significant debt and was unable to prioritise his work as a self-employed picture framer. Mr A was the main carer for his disabled wife, whom he believed did not know about his extramarital activities. She did, however, urge him to seek treatment for his low mood and irritability, a fact that influenced his decision to ask for help with his paraphilia. 
The Abel Assessment for Sexual Interest (AASI) (Abel 1998) is a less intrusive alternative to PPG, measuring length of time a person spends looking at various images presented to them on a computer screen.

\section{Cognitive tests}

Cognitive tests such as the Implicit Association Test (IAT) (Greenwald 1998) have been validated and are used to assess paedophilia and other paraphilias (Camilleri 2008). The IAT is based on the assumption that a person who holds a favourable view of a topic (e.g. sex with a child) is more likely to respond faster when sexual words are paired with child images compared with a person who does not hold such a view (Gray 2005).

Other psychometric tests, including personality measures such as the Minnesota Multiphasic Personality Inventory-2 (MMPI-2) (Butcher 2001), are useful in assessing specific difficulties and tailoring treatment.

In addition, many psychological tests, rating scales, questionnaires and inventories have been devised for the assessment of specific paraphilias (for a review see Laws \& O’Donohue 2008).

\section{Polygraph testing}

Polygraphy or 'lie detection' is widely used in the USA and is currently being introduced in England and Wales, following a successful pilot trial of mandatory polygraph testing of sex offenders released on probation (Gannon 2012). In addition to detecting reoffending if it occurs, polygraph testing of convicted sex offenders has been shown to provide more accurate information about the offender's history, improve the identification and targets of treatment, and enhance supervision by acting as a deterrent to reoffending (Grubin 2004).

\section{Differential diagnosis and treatment of comorbid conditions}

Occasionally, paraphilic behaviours and disorders are a feature of psychotic illness, organic mental disorder (e.g. dementia) or intellectual disability and developmental conditions such as autism spectrum disorder. In such cases, they should be managed in the context of the primary condition.

Patients seldom present voluntarily for treatment of paraphilias, owing to feelings of shame and low self-worth associated with their sexual fantasies and behaviours. Many initially present to mental health services with comorbid mental disorders such as anxiety, depression or substance misuse. Apparent resistance to treatment for their presenting disorder can turn out to be due to the presence of a paraphilia that the patient discloses during the course of therapy and that should be addressed in its own right.

\section{Risk assessment}

It is not our intention here to describe in detail the assessment and management of risk in sexual offenders. This has been comprehensively covered in two recent articles in this journal (Darjee 2012; Russell 2013).

The patient's history of offending must be documented and external sources of information should be sought to validate the patient's account. In general, patients who disclose illegal paraphilias should be referred for a forensic psychiatric opinion. Urgent referral may be needed if there are features of stalking or harassment, sadistic, rape or homicidal fantasies, or any escalation in worrying behaviours. Cases may be initially discussed with a forensic psychiatrist for advice on whether a formal forensic assessment is warranted, as referral criteria vary in different areas of the UK and within different jurisdictions.

Any matters concerning child protection should be discussed with the child protection lead and reported to children's services if this is indicated.

\section{Self-harm/suicide}

Risk of self-harm and suicide should always be assessed and carefully monitored in all patients with paraphilias, whether legal or illegal. The person may consider suicide a preferable option to fully owning up to and addressing their paraphilic interests and associated anxieties of being humiliated, rejected and ostracised.

\section{Confidentiality and disclosure}

Some patients present to health services for help with illegal paraphilic behaviours, such as exhibitionism or downloading child pornography, for which they have never been arrested or convicted, but in which they are continuing to engage. Others, who have been convicted and referred for subsequent treatment, may admit to their therapists that they are reoffending while in treatment without disclosing this to external agencies. Health professionals then need to decide whether or not to disclose this information to agencies within the criminal justice system (e.g. the police or probation service) and whether the mutli-agency public protection arrangements (MAPPA) system needs to be involved.

Any information-sharing or disclosure should be considered within the framework of professional guidance on confidentiality from the Royal College of Psychiatrists (2010), the General Medical Council (2009) and the Department of Health (2003, 
BOX 4 The Royal College of Psychiatrists' guidance on disclosure

Situations when it is justifiable for a psychiatrist to pass on patient information without consent or statutory authority include:

- where death or serious harm may occur to a third party, whether or not a criminal offence (e.g. disclosure of threat of serious harm to a named person, on the expectation that this would prevent the harm)

- when a disclosure may assist in the prevention, detection or prosecution of a serious crime, especially crimes against the person.

The definition of serious crime is not entirely clear, but would include murder, manslaughter, rape, treason, kidnapping, abuse of children and other vulnerable people or other cases where individuals suffer serious harm.

(Royal College of Psychiatrists 2010)

2010). These bodies advise that it may be justifiable for a doctor to pass on patient information without consent or statutory authority if there is a risk of serious harm without disclosure (Box 4).

Although the interpretation of 'serious harm' and 'serious crime' and the decision to disclose ultimately remain up to the individual clinician and local guidance, we would advocate that not all paraphilic sexual offences sufficiently satisfy the criteria of causing serious harm to justify disclosure without the patient's consent. In our experience, hasty decisions resulting in unnecessary disclosure can occur due to inadequate weighing of the risks of breaching confidentiality against the risk that the patient will cause harm to the public if disclosure does not occur. Disclosure without the patient's consent can have a negative effect on the therapeutic alliance with the individual - and with other patients, for example in group therapy - and on associated treatment benefits, including reduction of future offending (Box 5). The case should be discussed with other senior members of the team, the Caldicott guardian or a consultant forensic psychiatrist before the decision to disclose is made. The same considerations apply with regard to any request from an external agency such as MAPPA to disclose confidential information about a patient.

\section{Treatment}

\section{Biological approaches}

Research into effective treatments for paraphilias is limited and has mostly been conducted on samples of convicted sex offenders. Surgical castration was the most commonly used treatment for sex

offenders in a number of European countries until the 1970s and is still available in some US states, but was never embraced in the UK (Gordon 2008).

Anti-androgen medication in the form of cyproterone acetate, which can be administered orally or by depot injection, is available in most countries and, unlike surgical castration, its effects are reversible on discontinuation.

Luteinising hormone-releasing hormone (LHRH) agonists such as triptorelin and goserelin, which are given by depot and decrease testosterone levels, have been used in the treatment of sex offenders, with reported low levels of recidivism (Rousseau 1990; Dickey 1992; Thibaut 1993). Hormonal interventions may be indicated for paraphilias characterised by intense and frequent deviant sexual desire and arousal, which predispose the patient to severe paraphilic behaviour such as paedophilia or serial rapes (Thibaut 2010).

Antilibidinal drugs may also be used to treat sex offenders with intellectual disabilities or cognitive dysfunctions.

There is evidence for the use of selective serotonin reuptake inhibitors (SSRIs) (Grubin 2008), which also reduce male libido. The SSRIs may be particularly useful in paraphilias associated with obsessive-compulsive, impulse control or depressive disorders, or for individuals who experience a strong compulsive element to their paraphilic sexual urges that they find difficult to resist.

National and international guidelines for the biological treatment of paraphilias are available (e.g. Thibaut 2010), and all patients should have a thorough medical assessment and be monitored throughout treatment.

\section{BOX 5 The costs of unnecessary disclosure}

$\mathrm{Mr} B$ had a long history of voyeurism, in which he would hide in the women's toilets at his workplace and spy on them urinating. Although he had only ever been caught once and cautioned by the police but never convicted, he presented for help to his general practitioner and was referred to secondary mental health services. Following discussion with a forensic colleague, the assessing consultant psychiatrist came to the conclusion that Mr B's offending, which continued to be active, did not reach the threshold of serious harm to others to justify disclosure to the police and made the decision to refer to a specialist psychotherapy service for treatment, with the aim that this would reduce risk in the long term. However, in the process of applying for funding for this treatment, one of the commissioners unilaterally decided that $\mathrm{Mr} \mathrm{B}$ presented a safeguarding risk to children and vulnerable adults and informed the police and Mr B's place of work in the public sector.

Following police investigation, $\mathrm{Mr} \mathrm{B}$ was not charged owing to lack of evidence, but his employers decided that he was unsafe at work and he lost his job. Although funding for treatment was eventually approved, $\mathrm{Mr} B$ dropped out of treatment early, citing difficulties in trusting professionals. 


\section{Psychological approaches}

Although medication may be indicated for some sex offenders with paraphilias, the mainstay of treatment for paraphilias is psychological therapy, which offers the prospect of long-lasting change. Most of the research has focused on cognitivebehavioural interventions, which have been shown to offer a modest reduction in recidivism in sex offenders.

A meta-analysis of 69 studies of controlled outcome evaluations of sex offender treatments involving 22181 participants reported a 37\% reduction in sexual recidivism in treated groups (Losel 2005). Factors that predicted positive outcomes included treatment programmes that were specifically designed for sex offenders, group therapy and use of a cognitive therapy orientation.

Another review, based on a meta-analysis of 23 recidivism outcome studies, examined whether the risk-need-responsivity (RNR) principles associated with effective treatments for general offenders also applied to sexual offenders (Hanson 2009). Programmes that adhered to the RNR principles showed the largest reductions in sexual and general recidivism. However, evidence for the long-term effectiveness of cognitive-behavioural therapy (CBT) in sex offenders is less robust (Brooks-Gordon 2006) and the majority of studies relate to the treatment of sex offenders in general rather than individuals with specific paraphilias.

Cognitive-behavioural therapy

Cognitive-behavioural interventions for sex offenders have included social skills training, cognitive restructuring, development of victim empathy and imaginal desensitisation. In some motivated individuals, behaviour modification techniques such as covert desensitisation and minimal arousal conditioning have been reported to reduce deviant sexual arousal and replace it with appropriate arousal (Laws 2008).

\section{Relapse prevention therapy}

Relapse prevention therapy programmes specifically for sex offenders have been developed from CBT principles (Federoff 2010). Therapeutic programmes focus less on victim empathy and more on evidence-based dynamic factors such as intimacy, attachment, emotion regulation and impulsivity, as well as paying attention to the therapeutic relationship and attitudes of the staff.

\section{Good Lives Model}

The Good Lives Model of Offender Rehabilitation (GLM) (Ward 2006b) has increasingly gained prominence, and studies support its utility in sexual offender rehabilitation (Willis 2011). The GLM is a strengths-based approach to offender rehabilitation that aims to equip offenders with the skills necessary to attain inherently human and normal desires in personally meaningful and socially acceptable ways.

\section{Psychodynamic therapy}

Very few empirical studies have examined the efficacy of psychodynamic or insight-oriented psychotherapy for paraphilias. However, this lack of evidence does not mean that psychodynamic approaches are ineffective.

Psychodynamic therapy explores the intrapsychic and interpersonal dynamics that underlie the individual's paraphilic behaviours and fantasies in relation to their history and current relationships, including that with the therapist. Psychodynamic approaches may also be helpful in case assessment and formulation, in staff supervision and in providing a framework for delivery of other treatment modalities, such as CBT.

\section{Service provision}

Specialised services for the treatment of paraphilias are scarce in the UK, and most individuals gain access to treatment only after they have offended. Most treatment services for people who have been convicted of illegal paraphilias are located within the criminal justice system. These sex offender treatment programmes, mostly underpinned by cognitive-behavioural principles and delivered via group therapy, usually focus on the reduction of risk or rates of recidivism rather than improvements in mental health, although newer programmes do try to enable the person to improve their psychosexual and social functioning. Some forensic mental health services offer specialised sex offender treatment services, but provision across the UK is patchy. A key challenge is to enable clinical and criminal justice agencies to work together in a more integrated way. Although there are some examples of excellent practice (e.g. Minoudis 2012), this area needs further development.

Specific treatment services within the National Health Service for patients with legal paraphilias are even more limited. Some patients may be treated in psychosexual clinics, others within general psychology and psychotherapy departments. A few may be referred to specialised forensic psychotherapy services such as the Portman Clinic in London. Treatment may be in the form of individual, group or couple therapy. 


\section{Conclusions}

Paraphilias occupy an uneasy place in psychiatric nosology. Nevertheless, we believe that some individuals who experience unusual and distressing sexual fantasies, impulses and behaviours should be classified as having a mental disorder and we welcome the inclusion of the category of paraphilic disorders in DSM-5. However, further research is needed to elucidate the aetiology and prevalence of paraphilias and to develop and evaluate effective treatments for paraphilic disorders.

Service provision, especially for legal paraphilic disorders, remains limited in the UK and is at risk of being further reduced as a result of the changes in mental health service commissioning in a climate of economic austerity in which the treatment for such disorders is unlikely to be prioritised.

\section{References}

Abel GG, Huffman J, Warberg G, et al (1998) Visual reaction time and plethymography as measures of sexual interest in child molesters. Sexual Abuse: A Journal of Research and Treatment, 10: 81-95.

Abracen J, Looman J, Anderson D (2000) Alcohol and drug abuse in sexual and nonsexual violent offenders. Sexual Abuse: A Journal of Research and Treatment, 12: 263-74.

Ahlmeyer S, Kleinsasser D, Stoner J, et al (2003) Psychopathology of incarcerated sex offenders. Journal of Personality Disorder, 17: 306-18.

American Psychiatric Association (2000) Diagnostic and Diagnostic and Statistical Manual of Mental Disorders (4th edn, Text Revision) (DSMIV-TR). APA.

American Psychiatric Association (2013a) Diagnostic and Statistical Manual of Mental Disorders (5th edn) (DSM-5). APA.

American Psychiatric Association (2013b) Paraphilic Disorders Fact Sheet - DSM-5. APA

Bhugra D, Popelyuk D, McMullen I (2010) Paraphilias across cultures: Contexts and controversies. Journal of Sex Research, 47: 242-56.

Blanchard R, Watson MS, Choy A, et al (1999) Pedophiles: mental retardation, maternal age and sexual orientation. Archives of Sexual Behavior, 28: 111- 27.

Bogaerts S, Vanheule S, Declercq F (2005) Recalled parental bonding, adult attachment style and personality disorders in child molesters: a comparative study. Journal of Forensic Psychiatry and Psychology, 16: 445-58.

Bogaerts S, Vanheule S, Leeuw F, et al (2006) Recalled parental bonding and personality disorders in a sample of exhibitionists: a comparative study. Journal of Forensic Psychiatry and Psychology, 17: 636-46.

Bogaerts S, Daalder A, Vanheule S, et al (2008) Personality disorders in a sample of paraphilic and nonparaphilic child molesters: a comparative study. International Journal of Offender Therapy and Comparative Criminology, 52: 21-30.

Brooks-Gordon B, Bilby C, Wells H (2006) A systematic review of psychological interventions for sex offenders $-\mathrm{I}$. Randomised controlled trials. Journal of Forensic Psychiatry, 17: 442-66.

Butcher JN, Graham JR, Ben-Porath YS, et al (2001) Minnesota Multiphasic Inventory-2: Manual for Administration, Scoring and Interpretation (Revised Edition). University of Minnesota Press.

Camilleri JA, Quinsey VL (2008) Pedophila: assessment and treatment. In Sexual Deviance: Theory, Assessment and Treatment (eds R Laws, WT O'Donohue): 183-212. Guilford Press.

Cantor JM, Blanchard R, Christensen BK, et al (2004) Intelligence, memory and handedness in pedophilia. Neuropsychology, 18: 3-14.
Chantry K, Craig RJ (1994) Psychological screening of sexually violent offenders with the MCMI. Journal of Clinical Psychology, 50: 430-5.

Chaplin TC, Rice ME, Harris GT (1995) Salient victim suffering and the sexual responses of child molesters. Journal of Consulting and Clinical Psychology, 63: 249-55.

Cohen LJ, Nikiforov K, Gans S, et al (2002) Heterosexual male perpetrators of child sexual abuse: a preliminary neuropsychiatric model. Psychiatric Quarterly, 73: 313-36.

Darjee R, Russel K (2012) What clinicians need to know before assessing risk in sexual offenders. Advances in Psychiatric Treatment, 18: 467-78. Department of Health (2003) Confidentiality: NHS Code of Practice. Department of Health.

Department of Health (2010) Confidentiality: NHS Code of Practice. Supplementary Guidance on Public Interest Disclosures. Department of Health.

Dickey R (1992) The management of a case of treatment-resistant paraphilia with a long-acting LHRH agonist. Canadian Journal of Psychiatry, 37: 567-9.

Dietz PE, Evans B (1982) Pornographic imagery and prevalence of paraphilia. American Journal of Psychology, 139: 1493-5.

Dreznick MT (2003) Heterosocial competence of rapists and child molesters: a meta-analysis. Journal of Sex Research, 40: 170-8.

Dunn N, Seaburne-May M, Gatter P (2012) Internet sex addiction: a licence to lust? Advances in Psychiatric Treatment, 18: 270-7.

Dunsieth NW, Nelson EB, Brusman-Lovins LA, et al (2004) Psychiatric and legal features of 113 men convicted of sexual offenses. Journal of Clinical Psychiatry, 65: 293-300.

Federoff JP (2009) The paraphilias. In New Oxford Textbook of Psychiatry (2nd edn) (eds MG Gelder, NC Andreasen, JL Lopez-lbor, et al): 832-42. Oxford University Press.

Federoff JP, Marshall WL (2010) Paraphilias. In Cognitive-Behavioural Therapy for Refractory Cases: Turning Failure into Success (eds D McKay, JS Abramowitz, S Taylor): 369-84. American Psychological Association. Finkelhor D (1984) Child Sexual Abuse: New Theory and Research. Free Press.

Frances A, First MB (2011) Paraphilia NOS, nonconsent: not ready for the courtroom. Journal of the American Academy of Psychiatry and the Law, 39: 555-61.

Gannon TA, Wood J, Pina A, et al (2012) The Evaluation of the Mandatory Polygraph Pilot (Ministry of Justice Research Series 14/12). Ministry of Justice.

General Medical Council (2009) Confidentiality. GMC.

Gordon $\mathrm{H}$ (2008) The treatment of paraphilias: an historical perspective. Criminal Behaviour and Mental Health, 18: 79-87.

Gray NS, Brown AS, MacCulloch MJ, et al (2005) An implicit test of the associations between children and sex in pedophiles. Journal of Abnormal Psychology, 114: 304-8.

Greenwald AG, McGhee JL, Schwartz JL (1998) Measuring individual differences in implicit cognition: the Implicit Association Test. Journal of Personality and Social Psychology, 74: 1464-80.

Grubin D, Madsen L, Parsons S, et al (2004) A prospective study of the impact of polygraphy on high-risk behaviours in adult sex offenders. Sexual Abuse: A Journal of Research and Treatment, 16: 209-22.

Grubin D (2008) Medical models and interventions in sexual deviance. In Sexual Deviance: Theory, Assessment and Treatment (eds R Laws, WT O'Donohue): 594-610. Guilford Press.

Guidry LL, Saleh FM (2004) Clinical considerations of paraphilic sex offenders with comorbid psychiatric conditions. Sexual Addiction and Compulsivity, 11: 21-34.

Hall GCN, Hirschman R (1992) Sexual aggression against children: a conceptual perspective of etiology. Criminal Justice and Behavior, 19: 8-23. Hanson RK, Morton-Bourgon K (2004) Predictors of Sexual Recidivism: An Updated Meta-Analysis (Research Rep. No. 2004-02). Public Safety and Emergency Preparedness Canada. 


\section{MCO answers \\ $1 \mathrm{~d} \quad 2 \mathrm{e} \quad 3 \mathrm{a} \quad 4 \mathrm{a} \quad 5 \mathrm{~b}$}

Hanson RK, Harris AJR, Scott T, et al (2007) Assessing the Risk of Sexual Offenders on Community Supervision: The Dynamic Supervision Project. User Report 2007-05. Department of the Solicitor General of Canada.

Hanson RK, Bourgon G, Helmus L, et al (2009) The principles of effective correctional treatment also apply to sexual offenders: a meta-analysis. Criminal Justice and Behavior, 36: 865-91.

Hill A, Habermann N, Berner W et al (2007) Psychiatric disorders in single and double sexual murderers. Psychopathology, 40: 22-8.

Jesperson AF, Lalumiere ML, Seto MC (2009) Sexual abuse history among adult sex offenders and non-sex offenders: a meta-analysis. Child Abuse and Neglect, 33: 179-92.

Kafka MP (1997) Hypersexual desire in males: an operational definition and clinical implications for men with paraphilias and paraphilia-related disorders. Archives of Sexual Behavior, 26: 505-26.

Kafka MP, Hennen J (2002) A DSM-IV Axis I comorbidity study of males $(\mathrm{n}=120)$ with paraphilias and paraphilia-related disorders. Sexual Abuse: A Journal of Research and Treatment, 14: 349-66.

Kafka MP, Hennen J (2003) Hypersexual desire in males: are males with paraphilias different from males with paraphilia-related disorders? Sexual Abuse: A Journal of Research and Treatment, 15: 307-21.

Kinsey A, Pomeroy W, Martin C (1948) Sexual Behaviour in the Human Male. Saunders.

Kinsey A, Pomeroy W, Martin C, et al (1953) Sexual Behaviour in the Human Female. Saunders.

Kruger HC, Schiffer B (2011) Neurocognitive and personality factors in homo- and heterosexual pedophiles and controls. Journal of Sexual Medicine, 8: 1650-59.

Langevin R, Wortzman G, Dickey R, et al (1988) Neuropsychological impairment in incest offenders. Annals of Sex Research, 1: 401-15.

Langevin R, Wortzman G, Wright P, et al (1989) Studies of brain damage and dysfunction in sex offenders. Annals of Sex Research, 2: 163-79.

Langstrom N, Zucker KJ (2005) Transvestic fetishism in the general population: prevalence and correlates. Journal of Sex and Marital Therapy, 31: 87-95.

Langstrom N. Hanson R (2006a) High rates of sexual behaviour in the general population: correlates and predictors. Archives of Sexual Behaviour, 35: 37-52

Langstrom N, Seto MC (2006b) Exhibitionistic and voyeuristic behaviour in a Swedish national population survey. Archives of Sexual Behaviour 35: 427-35.

Laws R, O'Donohue WT (eds) (2008) Sexual Deviance: Theory, Assessment and Treatment. Guilford Press.

Leue A, Borchard B, Hoyer J (2004) Mental disorders in a forensic sample of sexual offenders. European Psychiatry, 19: 123-30.

Looman J, Abracen J, DiFazio R, et al (2004) Alcohol and drug abuse among sexual and nonsexual offenders: relationship to intimacy deficits and coping strategy. Sexual Abuse: Journal of Research and Treatment, 16: $177-89$

Losel F, Schmucker M (2005) The effectiveness of treatment for sex offenders: a comprehensive meta-analysis. Journal of Experimental Criminology, 1: 117-46.

Lyn TS, Burton DL (2004) Adult attachment and sexual offender status. American Journal of Orthopsychiatry, 74: 150-9.

Maes M, Van West D, De Vos N, et al (2001a) Lower baseline plasma cortisol and prolactin together with increased body temperature and higher mCPP-induced cortisol response in men with pedophilia. Neuropsychopharmacology, 24: 37-46.

Maes M, De Vos N, Van Hunsel F, et al (2001b) Pedophilia is accompanied by increased plasma concentrations of catecholamines, in particular epinephrine. Psychiatric Research, 103: 43-9.

Marsa F, O'Reilly G, Carr A, et al (2004) Attachment styles and psychological profiles of child sex offenders in Ireland. Journal of Interpersonal Violence, 19: 228 -51.

Marsh PJ, Odlaug BL, Thomarios N, et al (2010) Paraphilias in adult psychiatric inpatients. Annals of Clinical Psychiatry, 22: 129-34.
Marshall WL, Barbaree HE (1990) An integrated theory of the etiology of sexual offending. In Handbook of Sexual Assault: Issues, Theories, and Treatment of the Offender (eds WL Marshall, DR Laws, HE Barbaree): 257-75. Plenum Press.

Marshall WL, Marshall LE (2000) The origins of sexual offending. Trauma, Violence, and Abuse: A Review Journal, 1: 250-63.

Marshall WL (2006) Clinical and research limitations in the use of phallometric testing with sexual offenders. Sex Offender Treatment, 1: 1-32

Middleton D, Mandeville-Norton R, Hayes E (2009) Does treatment work with internet sex offenders? Emerging findings from the Internet Sex offender treatment programme (i-SOTP). Journal of Sexual Aggression, 15: 5-9

Minoudis P, Shaw J, Craissati J (2012) The London Pathways Project: Evaluating the effectiveness of a consultation model for personality disordered offenders. Criminal Behaviour and Mental Health, 22: 218-32.

O'Donohue WT, Regev L, Hagstrom A (2000) Problems with the DSMIV diagnosis of pedophilia. Sexual Abuse: A Journal of Research and Treatment, 12: 95-105.

Ogloff JRP, Cutajar MC, Mann E, et al (2012) Child Sexual Abuse and Subsequent Offending and Victimisation: A 45 Year Follow-Up Study. Australian Institute of Criminology.

Raymond NC, Coleman E, Ohlerking F, et al (1999) Psychiatric comorbidity in pedophilic sex offenders. American Journal of Psychiatry, 156: $786-8$

Rousseau L, Couture M, Dupont A, et al (1990) Effect of combined androgen blockade with an LHRH agonist and flutamide in one severe case of male exhibitionism. Canadian Journal of Psychiatry, 35: 338-41.

Royal College of Psychiatrists (2010) Good Psychiatric Practice: Confidentiality and Information Sharing (2nd edn) (College Report CR160). Royal College of Psychiatrists.

Russell K, Darjee R (2013) Practical assessment and management of risk in sexual offenders. Advances in Psychiatric Treatment, 19: 56-66.

Ruszczynski R (2007) The problem of certain psychic realities: aggression and violence as perverse solutions. In Lectures on Violence, Perversion and Delinquency (eds D Morgan, S Ruszczynski). Karnac.

Schiffer B, Peschel T, Paul T, et al (2007) Structural brain abnormalities in the frontostriatal system and cerebellum in pedophilia. Journal of Psychiatric Research, 41: 753-62.

Seto M C, Lalumière ML (2010) What is so special about male adolescent sexual offending? A review and test of explanations using meta-analysis. Psychological Bulletin, 136: 526-75.

Suchy Y, Whittaker JW, Strassberg DS, et al (2009) Neurocognitive differences between pedophilic and nonpedophilic child molesters. Journal of the International Neuropsychological Society, 15: 248-57.

Thibaut F, Cordier B, Kuhn JM (1993) Effect of a long-lasting gonadotrophin hormone-releasing hormone agonist in six cases of severe male paraphilia. Acta Psychiatrica Scandinavica, 87: 445-50.

Thibaut F, de la Barra F, Gordon H, et al (2010) The World Federation of Societies of Biological Psychiatry (WFSBP) Guidelines for the biological treatment of paraphilias. World Journal of Biological Psychiatry, 11: $604-55$.

Ward T, Siegert RJ (2002) Toward a comprehensive theory of child sexual abuse: a theory knitting perspective. Psychology, Crime and Law, 8: 319-51

Ward T, Beech A (2006a) An integrated theory of sexual offending. Aggression and Violent Behavior 11: 44-63.

Ward T, Gannon T (2006b) Rehabilitation, etiology, and self-regulation: the Good Lives Model of rehabilitation for sexual offenders. Aggression and Violent Behavior, 11: 77-94.

Willis GM, Ward T (2011) Striving for a good life: the good lives model applied to released child molesters. Journal of Sexual Aggression, 17: 290-303.

Wood $\mathrm{H}$ (2013) The nature of the addiction in 'sex addiction' and paraphilias. In Addictive States of Mind (eds M Bower, R Hale, H Wood). Karnac. 
World Health Organization (1992) International Classification of Mental and Behavioural Disorders, Tenth Edition (ICD-10). WHO.

Wright P, Nobrega J, Langevin R, et al (1990) Brain density and symmetry in pedophilic and sexually aggressive offenders. Annals of Sex Research, 3: $319-28$
Zander T (2008) Commentary: Inventing diagnosis for civil commitment of rapists. Journal of the American Academy of Psychiatry and the Law, 36: 459-69.

Zonana H (2011) Sexual disorders: new and expanded proposals for the DSM-5 - do we need them? Journal of the American Academy of Psychiatry and the Law, 39: 245-9.

\section{MCQs}

Select the single best option for each question stem

1 Regarding specific paraphilias:

a paedophilia is always illegal

b coprophilia is illegal

c a patient with exhibitionistic disorder who continues to expose himself should be under MAPPA

$\mathrm{d}$ gender identity disorder is not a paraphilia

e frotteuristic disorder may be diagnosed if the behaviour has been present for at least 3 months.

\section{DSM-5:}

a has included a new category of paraphilic coercive disorder for people who experience recurrent and intense sexual arousal from sexual coercion

b confines transvestic disorder to heterosexual males c categorises paraphilias on the basis of behaviours

d differentiates a paraphilic disorder from a paraphilia in terms of the distress caused to others

e gives diagnostic criteria for more specific paraphilias than ICD-10.

\section{Paraphilias:}

a may be viewed as culture-bound syndromes

b are more prevalent in the 21st century because of the internet

$c$ are very rare in women

d are any sexual desires or behaviours that cause the person to feel distress or involve another person's distress

e are associated with Cluster A personality disorders.

4 Regarding the aetiology of paraphilias: a early attachments difficulties have been associated with the later development of paraphilias

b specific paraphilias have been linked with specific cognitive deficits

c psychodynamic models are outdated

d neurodevelopmental models have the best evidence

e the majority of people with paraphilic disorders have a history of childhood sexual abuse.

5 In the management and treatment of paraphilic disorders:

a illegal paraphilic offences must always be disclosed

b comorbid conditions should be identified and treated

c patients committing sexual offences should be treated by forensic services

$\mathrm{d}$ group therapy is always preferable to individual therapy

e treatment with LHRH increases victim empathy. 